\title{
Summary of the Development of Chinese Think Tank Chanti Wu
}

(Ningbo Dahongying University, Ningbo, Zhejiang 315175)

\begin{abstract}
This paper explores the construction and development of the think tank system from the perspectives of research focus and important research conclusions from reading through the relevant literature between 2004 and 2015, and they are as follows: the factors that influence decision-making of think tank and evaluation mechanism of think tank research. Now development of think tank still has shortcomings, especially in the system, funds and so on. Secondly, there is no obvious importance understanding of think tank, and there are also some shortcomings in research of operation mechanism and evaluation mechanism of think tank.
\end{abstract}

Keywords: Think tank development; Influencing factors; Evaluation mechanism; Research review

\section{中国智库发展研究综述}

\author{
伍婵提 \\ (宁波大红鹰学院，浙江 宁波 315175)
}

摘要: 通览 2004-2015 年间有关智库发展的相关文献, 从研究重心与重要研究结论的视角对智库体系的构建与发展进行 了梳理, 分别是: 关于影响智库参与决策的因素研究和智库评价机制的研究。如今智库的发展仍旧存在不足之处, 尤其是在 制度以及资金等方面。其次是对于智库的重要性没有明显的认识，对于智库运行机制及评价机制的研究也存在不足。

关键字: 智库发展; 影响因素; 评价机制; 研究综述

中图分类号:C931 文献标志码:A

引言

“智库” 来源于 “Think”一词，是美国兰德公司于 1967 年 6 月首创。“智库” 在我国也称思想库、 脑库、智囊团。一般定义为由多学科的专家组成的, 为决策者在处理社会、经济、科教、军事、外交等各 方面问题出谋划策, 提供最佳理论、策略、方法、思想等的公共研究机构, 是独立于政府、团体及政党以 外的, 从事公共政策研究, 为政府出 “点子”、造 “主义” 的组织。

国内关于智库的研究工作起步于 20 世纪 80 年代初。智库研究的第一阶段自 1982 年起开始, 有关研 究选题基本上属于智库知识的普及推广以及对国外著名智库的常识性介绍 (朱锋、王丹若, 1990; 范贤睿, 2000; 中国现代国际关系研究所，2003、2004）。其后相当长的时间, 国内关于智库的研究工作一直局限 于对欧美等发达国家智库的情况介绍及一般性的历史回顾、案例分析和比较分析。进入 21 世纪后，国内 关于智库的研究工作向高级阶段提升。同时国内的关于智库的研究文文献也明显增多, 研究方向更加注重 国内的智库发展, 研究程度也不断加深。经过整理 2004 年至 2015 年的数据得出一下结论：

2004--2015 年智库主题研究进展

\begin{tabular}{|c|l|l|l|}
\hline & 年份 & 研究重心 & 主要研究结论 \\
\hline \multirow{3}{*}{ 探 } & 2004 & 中国外交智库角色 & 扩大智库政治参与度 \\
\cline { 2 - 4 } 期 & 2007 & 美国智库与贸易政策 & 智库在美国贸易中发挥着核心作用 \\
\cline { 2 - 4 } & 2008 & 日本智库外交作用 & 智库虽在日本外交中作用加重但阻碍犹大 \\
\cline { 2 - 4 } & 2009 & 美国教育智库 & 从影响对象与影响方式双维度促进智库发展 \\
\cline { 2 - 4 } & 2009 & 图书馆智库 & 利用优势全面展开新智库服务模式 \\
\hline
\end{tabular}




\begin{tabular}{|c|c|c|c|}
\hline \multirow{10}{*}{$\begin{array}{l}\text { 发 } \\
\text { 展 } \\
\text { 期 }\end{array}$} & 2010 & 智库建设与知识城市 & 智库与城市、人才彼此关联, 智库要担当第三方冷班子意识 \\
\hline & 2010 & $\begin{array}{l}\text { 智库成果评价体系-广东 } \\
\text { 省 }\end{array}$ & 新体系坚持了坚持实事求是在三方面促进积极发展 \\
\hline & 2010 & 中国智库 & 借鉴美国经验储备人才、提供政策支持、强化交流 \\
\hline & 2011 & 政策研究群体与政策制定 & 政策公开、综合协调 \\
\hline & 2011 & 农业信息智库 & $\begin{array}{l}\text { 农业制度建设的支撑、农业市场化保障、建设平台多元化投 } \\
\text { 入发展 }\end{array}$ \\
\hline & 2012 & 智库国际影响力与走向 & 发现问题、利用媒体与政府密切联系 \\
\hline & 2012 & $\begin{array}{l}\text { 中国智库低效率成因及破 } \\
\text { 解 }\end{array}$ & 注重团队分工、采用混合分工方式 \\
\hline & 2012 & 智库成果网络传播 & 智库成果实现发散交互传播的一个重要途径、多渠道传播 \\
\hline & 2013 & 国际格局与智库使命 & 搭建国际平台、交流促进共同进步 \\
\hline & 2013 & 智库与再生资源产业发展 & 创新建立智库联盟 \\
\hline \multirow{7}{*}{ 成 } & 2014 & 中国民间智库 SWOT 分析 & 提升自身实力形成专业特色、加强与政府合作 \\
\hline & 2014 & 新型城镇模式人文模式 & 利用媒体改进宣传方式、模式人文转化 \\
\hline & 2014 & 中国软实力 & 软实力促进中国发展、但相比欧美局限依旧很大 \\
\hline & 2015 & 军事战略智库 & 探索体系、构建战略智库运行机制、非固定人才提供 \\
\hline & 2015 & 中国民间智库 & 建立机制、增强专业水平、加强才队建设 \\
\hline & 2015 & 高校学科人才建设 & 加强学科人才建设、营造环境、创新理念构建主体结构 \\
\hline & 2015 & 外国专家知识运动员 & 拓展渠道、加强互动、树立证据观、强化体验 \\
\hline
\end{tabular}

纵观 12 年来全球关于智库主题相关的研究重心，可以将其分为三个阶段: 探索时期 (2004--2009), 该 阶段学者们主要针对智库在各国中某些领域发挥的作用, 研究层面狭窄, 研究力度不够, 研究领域比较分 散。这一时期的研究文献比较少。发展期 (2010--2013), 该阶段的学者主要研究的是智库在社会中各个层 面的实际应用, 更加看重智库的实际作用, 针对探索期的应用层面有了明显的扩展。成长期 (20014一至今), 该阶段学者对于智库的发展体系已经有了一个基本的整体观念。智库的发展体系已经形成, 学者们更多的 是针对与智库评价体系的完善, 以及针对与智库更深层次的发展转型。这一时期的研究保持持续增长, 并 且呈现一种持续向上的发展趋势。

在研究与发展中我国智库发展完成了以下三大转变:第一由国外到国内的转变。学者研究刚开始主要 针对于国外各国对于智库的应用, 研究的是智库在国外政治, 经济, 外交等大领域的作用。对于智库主要 是持借鉴的态度, 而现在研究从国外转到了国内, 发展时期的研究主要针对我国智库的发展, 对于国外的 关注度明显下降。智库研究由国外借鉴, 完成了向国内智库研究的一个国际性区域的转变; 第二, 由中央 到地方的层次性转变。我国起初智库的研究发展主要体现在国家经济, 政治, 国际性发展的层面, 智库的 应用发展大部分主要存留在中央内部, 对于地方的智库发展与应用存在明显不足。随着近年的发展, 智库 的应用已经完成了从中央到地方的广泛性深层次应用的转变; 第三, 由单纯的应用到完善延伸发展的转变。 智库在完成了由国外借鉴到国内应用和由中央到地方的层次性转变发展后，智库发展中的制度也由起初的 不完善, 逐步完善, 针对智库的一系列评价制度也逐渐完善。一系列的转变促使我国智库快速发展, 推动 了社会发展不断进步。

\section{1 影响智库参与决策的因素}

改革开放以来是中国智库发展最为迅速的时期，智库的发展一方面得益于我国哲学社会科学的发展与 繁荣，另一方面也得益于我国的决策者对于智库的重视。目前。中国已经有各类智库机构 2500 多家，正 式智库 426 家。但是无论是官方智库还是民间智库库亦或是高校智库，它们参与决策都受到诸多影响。 


\section{1 奖励机制与质量的影响}

随着大学规模和科研机构的扩大，中国发表的论文数量已经从 1995 年占全球科学期刊论文发表数量 的 $2 \%$ 上升到今天的 $8 \%$ 。但如果以论文的被引率和影响力作为评价指标, 中国科学研究的质量远远落后 于其数量。质量和数量之间产生差距的原因之一是源自中国现阶段对 “可见性成果” 的重视。现有的奖励 机制是, 刊发论文会有奖金, 如未能发表则可能导致失业, 这造成了劣质的研究泛滥以致更糟。在质量与 奖励机制的双重影响下，导致我国智库更难的走入决策层，使其发展举步维艰。

\section{2 经费以及与政府关系的影响}

从经费来源、得到资助的方式及与政府之间的关系来看，我们可以将中国的智库分为三种类型：“官 方”、“半官方” 和 “民间”。在上述三种类型中, 前二者属于 “体制内” 智库，吃财政饭，与决策者之 间有着密切的关系，基本上垄断了政府决策研究及话语权，其数量占 $95 \%$; 后者属于 “体制外” 智库，始 终要 “找米下锅”, 虽有较强的自主性和独立性, 但整体上非常弱小, 仅占总量的 5\%, 能够发出声音、有 一定社会影响力的更是零零无几。

长期以来，由于 “官本位”思想的影响，官方及社会对民间的“体制外”智库有一种歧视、排斥和不 信任心理，导致 “体制内” 智库一支独大而 “体制外” 智库却营生艰难。据有关统计资料，中央政府部门 81. 5\%的课题流向国务院及各部委所属的研究机构, 地方政府部门也有 $83.5 \%$ 的课题流向地方政府所属的研 究机构。由此可见, 政府部门的决策研究课题存在严重的 “内控” 现象。这样, 研究课题在体制内封闭发 表的方式下，“体制外” 智库完全成了 “局外人”，缺乏参与决策咨询竞争均等机会。

在经费以及政府观念的双重影响下，民间智库能参与决策的机会几乎是微乎其微。而同时的官方智库 则在政府的影响下, 其建议的影响度, 参与决策的实质度则大打折扣。从总体来说经费与政府观念阻碍了 智库参与决策进展。

\section{2 智库评价机制的研究}

成果评价工作是知识生产的重要环节, 对社会科学研究来说也是一个难题。对社会科学研究成果质量 和创新性的评价判断是比较复杂的, 不能简单地把自然科学的计量方法直接嫁接过来。2004 年中共中央颁 布了《关于进一步繁荣发展哲学社会科学的意见》, 各地方社科院以为契机。重树战略发展目标, 突出自 身特色, 完善运行机制, 打开研究思路, 坚持改革创新, 为打造新型政府智库做出探索和贡献。

在智库成果评价体系建设中, 袁安府等人指出建立社会科学研究成果评价指标体系, 要坚持三个基本 准则:一是定性评价与定量评价相结合; 二是形式评价与内容评价相结合; 三是理论与实践相结合。因此 针对社会科学研究成果开展质量评估和价值判断等活动, 必须根据不同的评价对象、评价内容和评价角度 来设计相对适用的评价指标体系。

目前, 我国还处于学术评价体系 “一统天下” 的状态, 大部分科研机构都以研究成果的纯学术水平为 评判依据, 较少针对成果的有用性和经济社会效益展开评价。邱均平和吴建华指出美国在社会科学的管理 上形成了一套相对完整、行之有效的管理体系; 建立了较完善的成果评价机制。在对成果评价的价值标准 中强调社会科学研究成果是否真正为社会发展和人民生活带来福利。赵珣在论文中指出我国社会科学评价 体系的发展呈现出从专家评估走向多元主体评估、从单维度评估走向多元标准评估、从主观评估走向主客 观综合评估、从阶段评估走向全过程评估等多种趋势。其中，“走向多元标准评估” 指的就是在不同角 
度、不同价值取向、不同业务目标的情况下来考量评价标准的设计问题。

\section{3 总结}

智库的发展对于一个国家的发展来说不仅仅是一把铜镜可以正衣冠，它的发展更是促进国家繁荣富强 的一块垫脚石。智库的发展对于任何国家来说都是不可忽略的, 尤其是高校智库的发展对于国家的发展具 有深远的作用。我国智库的发展过程中难免有些失误与不足, 这就需要政府以及社会各界, 同时也包括智 库本身不断发展与完善。相信在未来的发展中智库的发展会给我国的发展带来一个全新的方向, 促进我国 的进一步发展。

\section{4 致谢}

[基金]:浙江省教育科学规划 2015 年重点课题“地方高校智库建设与发展研究”阶段性成果(课题编 号:2015SB090)宁波市哲学社会科学学科带头人培育项目阶段性成果(课题编号:G15-XK21)

\section{Acknowledgments:}

This work was supported by key project of "2015 Zhejiang Education Science Planning"named Research on Construction and Development of Local University's Think Tank(Grant No. 2015SB090)and project of Cultivation of Ningbo Philosophy and Social Science Leaders (Grant No.G15-XK21).

\section{参考文献:}

[1] 胡光宇. 大学智库 [M]. 北京:清华大学出版社, 2015.1.

[2] 陈媛媛, 李刚, 关琳. 中外智库影响力评价研究述评 [J]。新疆师范大学学报 (哲学社会科学版), 2015 (4) : 35-45 莫 顿・凯勒，菲利斯・凯勒．哈佛走向现代:美国大学的崛起 [M]．北京:清华大学出版社，2007．237、237.

[3] 范东君. 坚持 “五个结合” 建设新型智库评价体系 [N]．中国社会科学报，2015-06-03(A05)

[4] 帕瑞克・克勒纳，韩万渠．智库概念界定和评价排名：函待探求的命题［J]．中国行政管理，2014(5) :25-28，33

[5] 崔玉军. 国外智库评价：理论与实践 $[J]$. 社会科学论坛，2015(11):19-33

[6] Abe1son, Donald E. 01d world, new world: the evolution and influence of foreign affairs think-tanks [J]. INTERNATIONAL AFFAIRS, 2014, $90(1):$ 125-142

[7] Luiz, JVR. Think Tanks in the United States and Critical Theory of the State [J]. ESPACI0 ABIERT0, 2015, $24(2): 275-296$

[8] Rossi, PJ, Gunduz, A and Judy, J. Proceedings of the Third Annual Deep Brain Stimulation Think Tank: A Review of Emerging Issues and Technologies [J]. FRONTIERS IN NEUROSCIENCE, 2016, 10 (2) :55-58

[9] 22. McLevey, J. Think Tanks, Funding, and the Politics of Policy Knowledge in Canada [J]. CANADIAN REVIEW OF SOCIOLOGY-REVUE CANADIENNE DE SOCIOLOGIE，2014，51(1) :54-75

\section{References:}

[1] Hu Guangyu, University Think Tank [M]. Beijing: Tsinghua University Press, 2015, 1.

[2] CHEN Yuan-yuan, Li Gang, Guan Lin, Review of Research in Appraisal of Chinese and Foreign Think Tank Influence [J]. Journal of Xinjiang Normal University (Edition of Philosophy and Social Sciences), 2015(4): 35-45. Morton Keller, Phyllis Keller, Harvard towards Modern: the Rise of American Universities [M]. Beijing: Tsinghua University Press, 2007, 237, 237.

[3] Fan Dongjun, Persist in "Five Combinations" and Construct New Think Tank Evaluation System [N]. Chinese Journal of Social Science, 2015-06-03(A05). 
[4] Patrick Koellner, Han Wanqu, Think Tanks: the Quest to Define and to Rank Them: Propositions to be Explored [J]. Chinese Public Administration, 2014(5): 25-28, 33.

[5] Cui Yujun, Evaluation of Foreign Think Tanks: Theory and Practice [J]. Tribune of Social Sciences, 2015(11): 19-33.

[6] Abelson, Donald E. Old world, new world: the evolution and influence of foreign affairs think-tanks [J]. INTERNATIONAL AFFAIRS, 2014, 90(1): 125-142

[7] Luiz, JVR. Think Tanks in the United States and Critical Theory of the State [J]. ESPACIO ABIERTO, 2015, 24(2):275-296

[8] Rossi, PJ, Gunduz, A and Judy, J. Proceedings of the Third Annual Deep Brain Stimulation Think Tank: A Review of Emerging Issues and Technologies [J]. FRONTIERS IN NEUROSCIENCE, 2016, 10(2):55-58

[9] 22. McLevey, J.Think Tanks, Funding, and the Politics of Policy Knowledge in Canada [J].CANADIAN REVIEW OF SOCIOLOGY-REVUE CANADIENNE DE SOCIOLOGIE, 2014, 51(1):54-75 